Témoigner Témoigner. Entre histoire et mémoire

Getuigen Revue pluridisciplinaire de la Fondation Auschwitz

$126 \mid 2018$

Questions sur l'avenir du travail de mémoire

\title{
Ik René Tardi herinneringen aan een krijgsgevangenschap (Jacques Tardi)
}

\section{Brecht Capiau}

\section{(2) OpenEdition}

1 Journals

Édition électronique

URL : https://journals.openedition.org/temoigner/7073

DOI : $10.4000 /$ temoigner.7073

ISSN : 2506-6390

\section{Éditeur :}

Éditions du Centre d'études et de documentation Mémoire d'Auschwitz, Éditions Kimé

\section{Édition imprimée}

Date de publication : 2 avril 2018

Pagination : 16-19

ISBN : 978-2-930953-06-9

ISSN : 2031-4183

\section{Référence électronique}

Brecht Capiau, «lk René Tardi herinneringen aan een krijgsgevangenschap (Jacques Tardi)», Témoigner. Entre histoire et mémoire [Online], 126 | 2018, Online op 24 janvier 2022, geraadpleegd op 04 février 2022. URL: http://journals.openedition.org/temoigner/7073 ; DOI: https://doi.org/10.4000/temoigner. 7073 


\section{IK RENÉ TARDI \\ HERINNERINGEN AAN EEN KRIJGSGEVANGENSCHAP \\ (JACQUES TARDI)}

STRIP In 2012 en 2015 publiceerde de Franse striptekenaar Jacques Tardi respectievelijk Ik René Tardi: krijgsgevangene in Stalag II B en het vervolg met als ondertitel Mijn terugkeer naar Frankrijk. Samen vertellen ze het wedervaren van René Tardi, vader van Jacques, tijdens de Tweede Wereldoorlog. Eerst als lid van een tankbemanning, later als krijgsgevangene met nummer 16402 in Stalag II B in Hammerstein, Oost-Pommeren. Het is wellicht het meest therapeutische striptweeluik voor Tardi, een artiest die is geobsedeerd door de

Wereldoorlogen en de rol van de gewone man daarin.

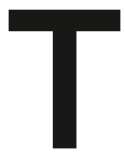

di gebruikt voor zijn striptweeluik niet alleen de herinneringen van zijn ader, die op aanraden van ijn zoon het doorstane leed in 1980 op schift stelde. Hij onderzoekt ook zijn eigen geheugen, en intromet korte broek. Via dat personage met korte broek. Via dat personage dialoog an met Ré Tardi Same bespreken ze zaken die tijdens het bespreken ze zaken die tjdens het zijn gekomen. De dialoog mondt zijn gekomen. De dialoog mond vaak uit in ruzie, omdat vader en Wereldoorlog elk vanuit hun Wereldoorlog elk vanuit hun eigen Werklaren. 列 . shap in een Stalag en later de hereniging met zijn 1945. Tijdr zijn odysee becommentarieert Re Th. Tijdens zijh odyssee beconmentarieert René to zijn gevangeid de gebeurtenissen die geleid hebben totajngevangenting
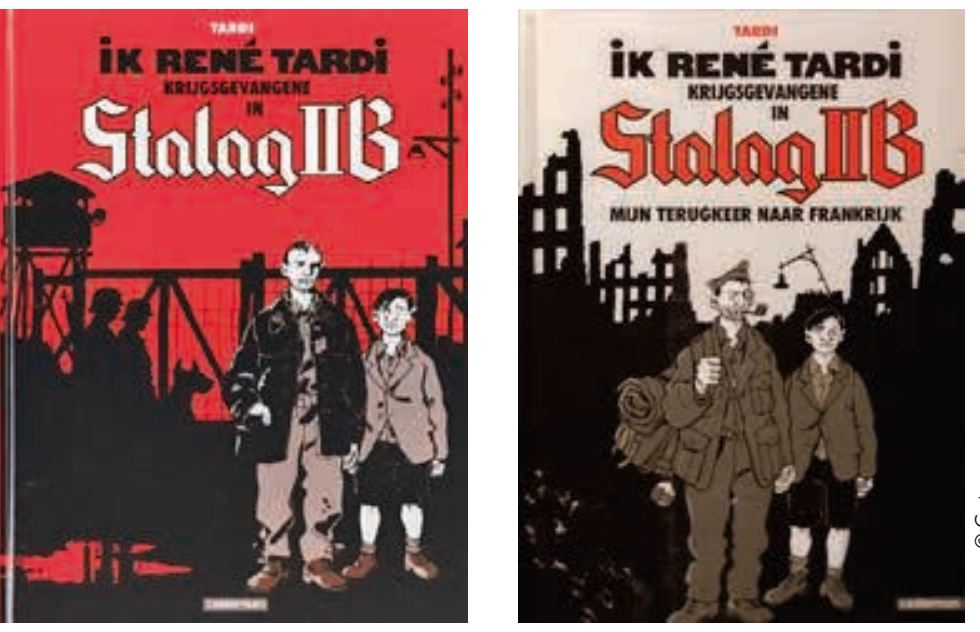

opvalt in de strip is dat Jacques Tardi zijn vader vaak zaken laat vertellen die hij op dat moment in het verhaal onmogelijk kan weten maar wel een brede Tistorisch kader bieden. Dit retrospectief procedé zal Tardiconsequent toepassen in het gehele tweeluik. De keuze van de auteur doet geen afbreuk aan de biogra-

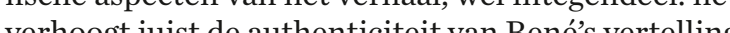

omdat de historische aanvullingen het persoonlijke verhaal voeden en versterken

Toonde de striptekenar Tardi zich al een mester in het annschouwelijk maken van de gruwel in ter in het anch loopgraven tijd van te van de horror in een Stalag. Zijn panoramische platen, van René Tardi, zorgen ervor dat je een goed beeld van René Tardi, zorgen ervoor dat je een goed beeld Het kan de routhes in een POW-gevangenenkamp. Jat the Jacques Tardi maalte over de Eerste Wereldoorlog. dit viij som, zwate vel tit vij son tweede luik Mijn terugheor andere kleuren aan bod. Wie denkt dat de plotselinge is eran voor de sonber is gedrente zoont die stripar in he waak die René en zejn strijdmakkers nemen op hun Duitse bewaks. De neest gehate onder hen worden zonder pardon opgeknopt. Het is het thieste velen op te tekenen zijn.

VAN VRIJWILLIGER TOT KRIJGSGEVANGENE

Zoon Jacques begint het verhaal van zijn vader in 1935, wanneer die zich vrijwillig aanmeldt bij het leger

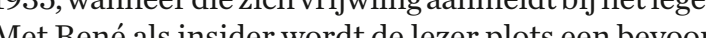
cet he als insider wist de rechte getuige van de visie van de Franse legerleiding op de nakende oor g. Samen met hem verwonderen we ons over het feit dat riank ten les krijgen in oude rammelkasten van tanks ren cerste Wereldoong. Ondanks ainn kitiek op de sta Wereldoorlog valt toch vooral de gretigheid va Tardi op die stat te trappran lat de Duitsers. Hij zal ze met zijn kleine Hotaks t 39 wel trol weens een lesje leren! Op 22 mei 1940, amper

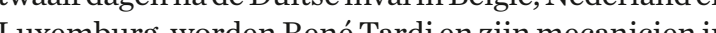
Lons-enter Mons-Chausseebij Pérone in de Somne uit hun ther Delange, uitputtendetochtnar het knjgserangenenHoew Jaches Tardin

eeluik kiest voo een zocor de belevenissen van zijn vader, neemt hij een loopje met de waarheid op het moment dat René in het verDulag XII D in Trier aankomt. Hier heeft hij een korte ontmoeting met Jean Grange, de latere che

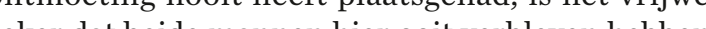
Dulag XII D in Trier was immers en bekend DurchDumg

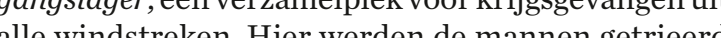

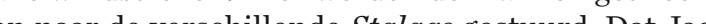
quar de verschillende Stalags gestuurd. Dat Jacen direct en diepe verbondente con vect var een artistieke hoogte stuwt.

Het valt op dat Jacques Tardi zijn vader niet bete (1) veel beter. Veel symp thie welt vader Re iet op bij de lezer. Het math hem wel zeer menselijk. De meesten onder ons zijn immers niet hensein. Dencesten ond ter op de prof st. Als dat wel gebeurt, zien we dat ter op de proef stelt. Als dat wel gebeurt, zien we dat veel mensen proberen om hun leven te organiseren van seur, an slen, als is dat niethet beeld dathet grote publick

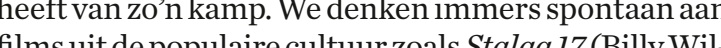
ler 1953) of The Great Escape (John Sturges, 1963). der, 1953) of The Great Escape (JohnSturges, 1963). I proze laatste film, gebaseerd op ware gebeurtenissen, proberen zeallither dnappen uithet kamp. De protagonisten zijn dapperder ha stalag koch snee Stalag komen amper aan bod, maar zijn volledig net ontsnapping. Het strekt Jacques Tardi dan ook tot eer dan heengen lats badden in het dagelijkse bestaan.

VAN KRIJGSGEYANGENE TOT YRIJ MAN

Hoewel Tardi's beschrijvende vertelstijl een zegen is voor het verhaal, is het jammer genoeg ook mige stripplaten zijn voor de helft bedekt met tekstballon, waardoor je de indruk krijgt dat je een- 

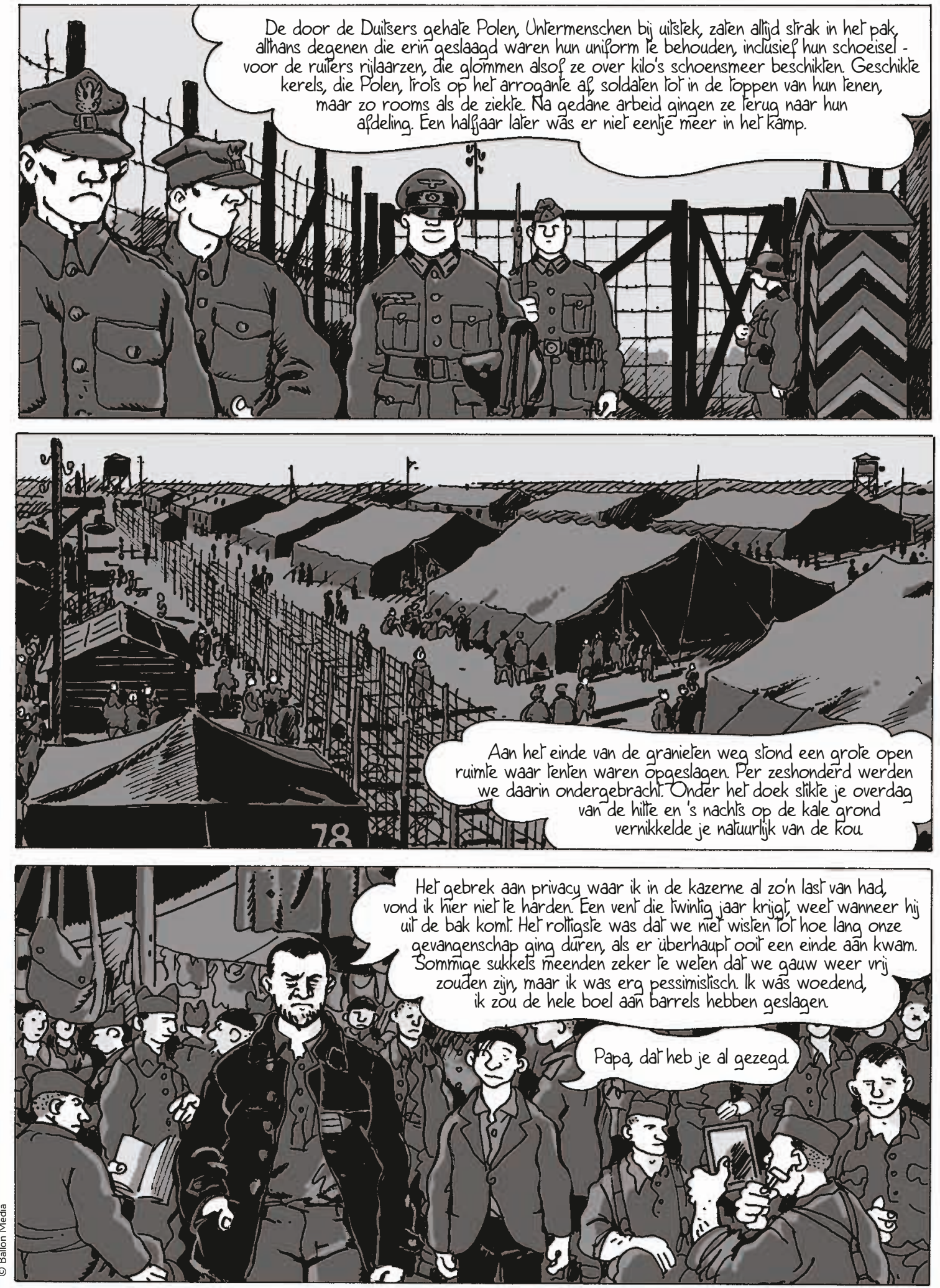

œ der een geïllustreerde roman aan het lezen bent dan een strip. Jacques Tardi heeft echter zoveel krediet bij zijn lezers dat hij er mee wegkomt. In het eerste

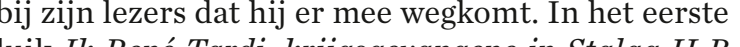
luik Ih René Tardi. hrijgsgewangene in Stalag II B althe be want ware beproeving. Bovenop de kon van het Stalag. Het vertragt het verhal anacuatie en is iet altijd toven interes en is nietalug en beeldend ne rom. Een slectievande meest bijzond dit album wordt gewag ge gest vap eet dende dan dit abu we Ta di ter genaakt van een derde deel, waarin Rene Tas gag niet verschenen.

Ik René Tardi: Krijgsgevangene in Stalag II B en Mijn terugkeer naar Frankrijk vormen samen het . strptekenaar Jacques Tardi over zijn gevangenschap in Stalag II B. In het uitgebreide voorwoord van het note van Jaccues Tardi, ons met de uiterst pijnlije mon na de oo Bitter fale Jen ha deorlog. Bittere spotenonbed waren zijn deel. Graven van de Eerste Werent had inmers de loopgrainis ba de Ear 1940. Pas vele jaren later vond Jean, die on van mei 1940. Pas vele jaren later vond Jean, die ondertussen emotioneel was dichtgeklapt, steun bij de uiterst respectvolle Rene Tadi. Een derijelijke thuiskomst was Renégespard Jean, de gruwelijkhed welonder woorden brengen. twee families, twee uiterst beiende verhalen. Niettemin gaat het verhal van Jean Grange, ondanks de moedige getuigenis van dochter Doninique, grotendeelsvenlon een selecte club mogen Brecht Capiau

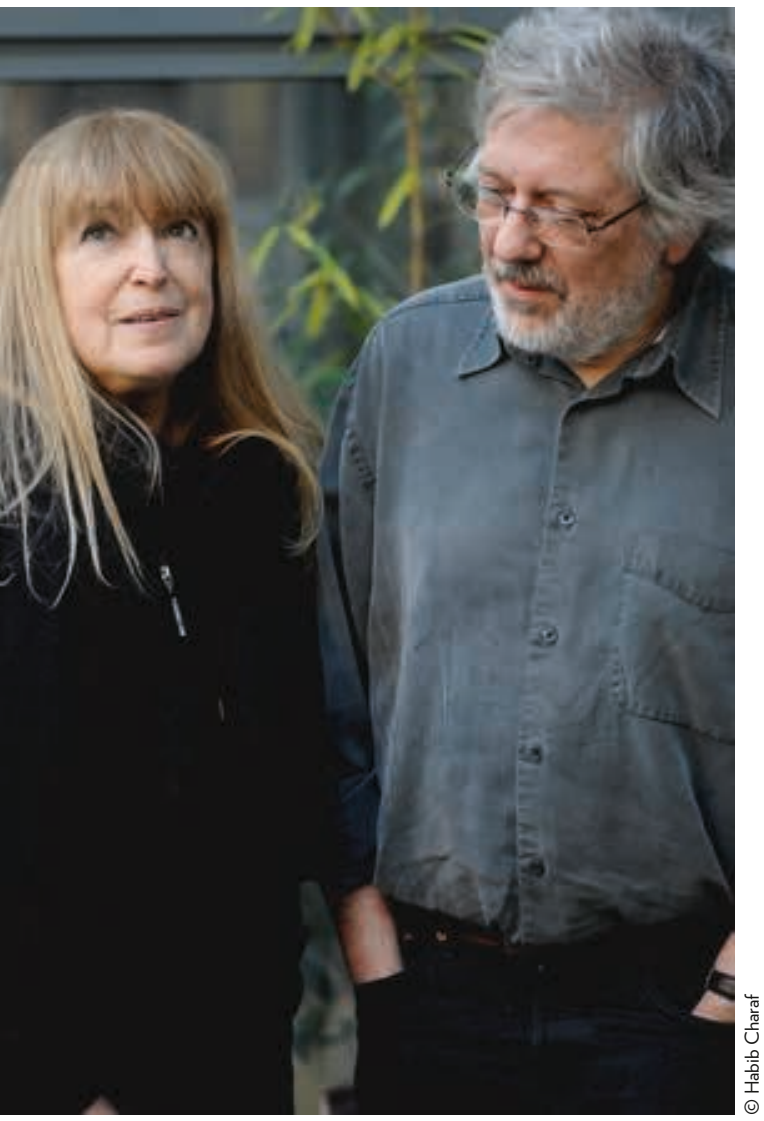

Dominique Grange en Jacques Tardi

$\rightarrow$ Meer weten

A Jacques Tardi, Ik René Tardi: krijgsgevangene in Stalag II B,
België: Casterman, 2012.

$\triangle$
Mijin terugueseer naar Frankrijk, Belgije: Casterman, 2015 